\title{
Molecular and Phytochemical Characterization of Andrographis paniculata Nees in Tirunelveli Hills in South India.
}

\author{
Rekha G. S. ${ }^{1}$ and John De Britto A. ${ }^{2 *}$ \\ ${ }^{12}$ Plant Molecular Biology Research Unit, PG and Research Department of Plant Biology and \\ Biotechnology, St.Xavier's College (Autonomous), Palayamkottai - 627002 Tamilnadu, India, E-Mail: \\ *bjohnde@yahoo.co.in (corresponding author) \\ Received on $31^{\text {st }}$ January 2008, accepted in revised form 15th March 2010.
}

\begin{abstract}
In the present study, Andrographis paniculata Nees was collected from ten locations in Tirunelveli hills and the genetic variability was investigated using RAPD-PCR fingerprint and the population which showed high percentage of polymorphism was selected. Those populations were chosen for further phytochemical analysis. The active principle in these plants has been quantified by HPLC analysis. The population which exhibited both high percentage of polymorphism and high amount of active principle was considered to be the superior genotype.
\end{abstract}

(Keywords: Andrographis paniculata Nees, genetic variability, RAPD, active principle, HPLC, superior genotype)

\section{INTRODUCTION}

Genetic diversity measurements are important for considering conservation of particular species. A decline in genetic variation can undermine the ability of an organism to respond to natural selection and consequently limits its evolutionary potential. Small populations are often subject to the loss of alleles through genetic drift, or random fluctuations in allele frequency. Kalmegh (Andrographis paniculata Nees) belonging to family Acanthaceae, is one of the most important herbs used in Indian traditional Ayurvedic and homeopathic system of medicine. Andrographolide and related compounds were investigated for their pharmaceutical properties and all showed varying degree of antipyretic, anti malarial and anti-inflammatory activity. Genetic improvement for quantitative traits in Kalmegh can be achieved through a clear understanding of the nature and amount of variability present in genotypes and the extent to which the desirable traits are heritable (Misra et al., 2000).

Andrographis paniculata (Burm.f.) Nees comes under the family Acanthaceae. The whole plant is used as medicine. It is useful in burning sensation, wounds, ulcer, chronic fever, malarial and intermittent fevers, inflammations, cough, bronchitis, skin diseases, leprosy, intestinal worms, colic, diarrhoea, dysentery. The plant contains flavanoids and andrographolides. Two flavanoids, identified as 5, 7, tetramethoxyflavanone and 5-hydroxy-7, trimethoxyflavone, as well as several other flavanoids, andrographolide diterpenoids and polyphenols, were obtained from the phytochemical investigation of the whole plant.

\section{MATERIALS AND METHODS}

The tender leaves of Andrographis paniculata were randomly collected from ten different places of Tirunelveli hills (Table 1.) The distance between two populations is $15 \mathrm{k} . \mathrm{m}$. Each population consisted of ten plants within a radius of $5 \mathrm{~m}$.

During collection, young leaves were collected in separate vials for RAPD analysis and stored in $-70^{\circ} \mathrm{C}$ until DNA was extracted and pooled as well as the entire plants were collected for the Herbarium preparation and also for the HPLC analysis. The specimens were compared and checked with the Herbarium of Botanical Survey of India (BSI), Coimbatore, Tamil Nadu in India.

\section{DNA ISOLATION}

The collected plant materials were taken to the lab and stored in $-70^{\circ} \mathrm{C}$. Then the DNA was extracted from these plants by CTAB (modified) 
Table1: Areas of collection and Accession ID of Andrographis paniculata

\begin{tabular}{|l|c|c|}
\hline Sl. No & Area & Accession ID \\
\hline 1 & Kalakad & 1 \\
\hline 2 & Karayar & 5 \\
\hline 3 & Manimuthar & 6 \\
\hline 4 & Agasthiyamalai & 2 \\
\hline 5 & PapanasamRF & 9 \\
\hline 6 & Courtallum & 10 \\
\hline 7 & Chenkottai & 3 \\
\hline 8 & PuliyurRF & 4 \\
\hline 9 & Kadayanalloor & 7 \\
\hline 10 & Vasudevanalloor & 8 \\
\hline
\end{tabular}

technique (Doyle and Doyle, 1987). The Absorbance at nanometers A260/A280 was read. It ranged from 1.5 to 1.9 .5 primers were used for amplification (table 2.). The amplification reaction was performed by 50ng of DNA, 15 picomoles of a single decamer random primers, PCR mixture and water to a total volume of $25 \mu 1$ in 2.5ml PCR tubes (Williams et al., 1990).

Table2: Primers used and their sequences for Andrographis paniculata

\begin{tabular}{|c|l|l|}
\hline Sl. No & Primer name & Primer sequences (5 to 3) \\
\hline 1 & OPX-3 & TGGCGCAGTG \\
\hline 2 & OPX-4 & CCGCTACCGA \\
\hline 3 & OPX-6 & ACGCCAGAGG \\
\hline 4 & OPX-12 & TCGCCAGCCA \\
\hline 5 & OPX-19 & TGGCAAGGCA \\
\hline
\end{tabular}

\section{ANALYSIS OF RAPD PROFILES}

PCR amplification was repeated at least two to three times for RAPD profiling and only reproducible, well-marked amplified fragments were counted. For quantification of diversity/similarity, pair wise comparisons of banding patterns were made by calculating indices of similarity (S) using the matching coefficient method of ${ }_{\mathrm{AB}}=2 \mathrm{X}$ Number of shared bands / Total number of bands. 
For RAPD finger printing, all samples were compared within the species collected from five different places. Data scored manually based on the presence and absence of bands. Comparisons were carried out between the samples amplified by the same primer in a pair wise manner. The similarity index between individuals was calculated following the method by $\mathrm{Nei}$ and $\mathrm{Li}$, (1979). Based on average matrices for all primers a dendrogram was obtained by using an Unweighed Pair Group Method Analysis (UPGMA) for genetic distances (Table 3.).

\section{ESTIMATION OF GENETIC DISTANCE}

Estimation of genetic distance within the populations was calculated using the Jaccard's distance co-efficient (Sneath and Sokal, 1973). This co-efficient calculates the $\%$ of the number of polymorphic markers between the populations. Dendrogram was drawn using the software Popgene package version 1.31 and the percentage of polymorphism was calculated by using the software.

Based on the primary data (presence or absence of bands), pair wise genetic identity and genetic distance between samples were calculated using Popgene package version 1.31. Dendrogram was constructed and analyzed.

In order to scrutinize further, the five populations, which showed the highest polymorphism, were selected for further HPLC. Leaves from the plants of these five populations were collected and shade dried and powdered.

\section{Quantification of Andrographolide}

Andrographolide quantification (Table.4) was based on the analysis of kvazimolecular ion $\mathrm{m} / \mathrm{z}$ $=361.12$ with an internal standard caffeine.

\section{RESULTS AND DISCUSSION}

The five primers used to analyze genetic variation in Andrographis paniculata produced 51 polymorphic bands (Plate.1). The same type of bands occurred at different frequencies in all populations. The genetic distance between the population ranged from 0.1724 to 0.9310 and the genetic identity ranged from 0.6897 to 0.9655 . The overall observed and effective number of alleles is about 1.65 and 1.26 respectively. Nei (1978) [9] overall gene diversity is 0.1724 .
The dendrogram of Andrographis paniculata (Figure 1) produced three clusters. Here population 1 and population 3 are ungrouped. The largest cluster consists of 4 sub groups. Here population 2 and 7 , population 4 and 6 , population 8 and 5 and population 9 and 10 are closely together. From this it is understood that there is considerable amount of genetic variability between the ten populations of Andrographis paniculata.

The number of polymorphic loci and percentage of polymorphism (Table.5) was calculated by using the software Popgene package version 1.31. Among these ten populations, populations 1, 5, 6, 9, and 10, (Kalakad, Karayar, Courtallum, Papanasam RF and Manimuthar) showed highest polymorphism.

Genetic variations within the population can sometimes allow a species to adapt to a changing environment. Genetic variability leads to longterm survival of species. It comes to the rescue of a species at crucial situations by lending genes that impart resistance, surveillance and higher productivity. It paves more and more avenues for crop improvement and hybridization. Species with little or no genetic variability will have greater tendency to go extinct, when a new disease, a new predator, or some other changes occur in the environment.

Consequences of low genetic variability are inbreeding depression, loss of evolutionary flexibility, and out breeding depression, all of which lend to weak, sterile individuals. Genetic variability paves more and more avenues for crop improvement and hybridization. Species with little or no genetic variability will have greater tendency to go extinct when a new disease, a new predator, or some other change occurs in the environment. Consequences of low genetic variability are inbreeding depression, loss of evolutionary flexibility, and outbreeding depression all of which lead to weak, sterile individuals.

Among these five samples $(1,5,6,9,10)$ population 10, which was collected from Courtallum, showed the highest amount of Andrographolide $(15.090 \mu \mathrm{g})$ followed by population 9, which was collected from Papanasam RF (11.077 $\mu \mathrm{g})$ (Table 6.). 
Malaysian Journal of Science 29 (1): 14-21 (2010)

Table 3: Nei's Unbiased Measures of Genetic Identity and Genetic distance in A. paniculata

\begin{tabular}{|c|c|c|c|c|c|c|c|c|c|c|}
\hline $\begin{array}{l}\text { Pop } \\
\text { ID }\end{array}$ & 1 & 2 & 3 & 4 & 5 & 6 & 7 & 8 & 9 & 10 \\
\hline 1 & $* * * *$ & 0.6897 & 0.6552 & 0.7586 & 0.6897 & 0.7241 & 0.7586 & 0.7241 & 0.7586 & 0.8276 \\
\hline 2 & 0.3716 & $* * * *$ & 0.6897 & 0.9310 & 0.8621 & 0.8966 & 0.9310 & 0.8966 & 0.7931 & 0.8621 \\
\hline 3 & 0.4299 & 0.3716 & $* * * *$ & 0.7586 & 0.6897 & 0.7241 & 0.6897 & 0.6552 & 0.6897 & 0.6897 \\
\hline 4 & 0.2763 & 0.0715 & 0.2763 & $* * * *$ & 0.9310 & 0.9655 & 0.9310 & 0.8966 & 0.7931 & 0.8621 \\
\hline 5 & 0.3716 & 0.1484 & 0.3716 & 0.0715 & $* * * *$ & 0.8966 & 0.8621 & 0.8276 & 0.7241 & 0.7941 \\
\hline 6 & 0.3228 & 0.1092 & 0.3228 & 0.0351 & 0.1092 & $* * * *$ & 0.8966 & 0.8621 & 0.7586 & 0.8276 \\
\hline 7 & 0.2763 & 0.0715 & 0.3716 & 0.0715 & 0.1484 & 0.1092 & $* * * *$ & 0.8966 & 0.7931 & 0.8621 \\
\hline 8 & 0.3228 & 0.1092 & 0.4229 & 0.1092 & 0.1892 & 0.1484 & 0.1092 & $* * * *$ & 0.8276 & 0.8966 \\
\hline 9 & 0.2763 & 0.2318 & 0.3716 & 0.2318 & 0.3228 & 0.2763 & 0.2318 & 0.1892 & $* * * *$ & 0.9310 \\
\hline 10 & 0.1892 & 0.1484 & 0.3716 & 0.1484 & 02318 & 0.1892 & 0.1484 & 0.1092 & 0.0715 & $* * * *$ \\
\hline
\end{tabular}

*Nei's genetic identity (above diagonal) and genetic distance (below diagonal). 


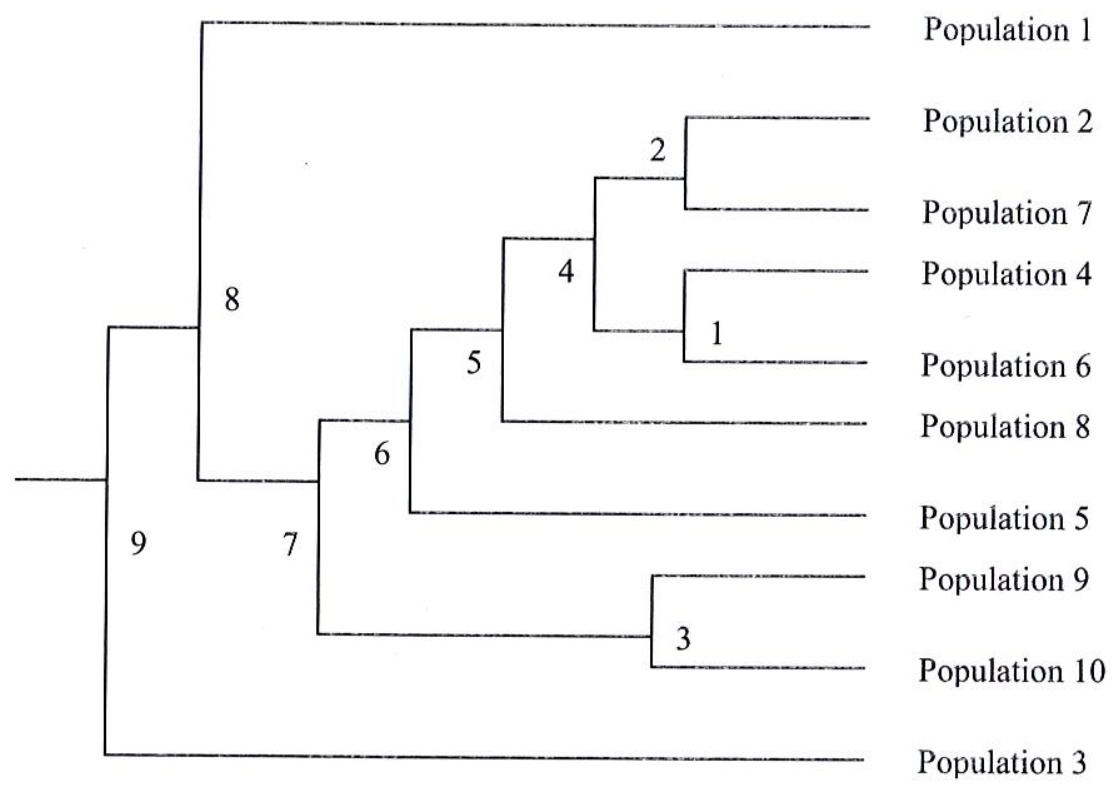

Figure 1: UMPGMA dendrogram of Andrographis paniculata based on Nei's Genetic distance derived from RAPD data.

Table 5: Number of polymorphic loci and percentage of polymorphism in Andrographis paniculata

\begin{tabular}{|c|c|c|}
\hline Population no & $\begin{array}{c}\text { Number of } \\
\text { polymorphic loci }\end{array}$ & $\begin{array}{c}\text { Percentage of } \\
\text { polymorphic loci }\end{array}$ \\
\hline 1 & 14 & 48.28 \\
\hline 2 & 9 & 31.03 \\
\hline 3 & 8 & 27.59 \\
\hline 4 & 10 & 34.48 \\
\hline 5 & 11 & 37.93 \\
\hline 6 & 12 & 41.38 \\
\hline 7 & 11 & 31.03 \\
\hline 8 & 10 & 34.48 \\
\hline 10 & 13 & 37.93 \\
\hline
\end{tabular}




\section{ACKNOWLEDGEMENT}

The authors are grateful to University Grants Commission, New Delhi and Indian National Science Academy, New Delhi for the financial assistance to carryout this research work. The authors are very grateful to Dr.Vilim Simanek and Dr.Pavel Kosina, Department of Chemistry, Palacky University, Olomouc, Czech Republic for helping in analyzing the samples using HPLC.

Table 6: Quantification of andrographolide in Andrographis paniculata dry plant samples carried out with $\mathrm{MS} / \mathrm{MS}$ detection.

\begin{tabular}{|c|c|c|c|c|}
\hline Sample & $\begin{array}{l}\text { Weight } \\
\text { for } \\
\text { extractio } \\
\text { n (g) }\end{array}$ & $\begin{array}{l}\text { Residuum } \\
\text { after } \\
\text { evaporation } \\
\text { (g) }\end{array}$ & $\begin{array}{l}\text { Determined w } \\
(\%) \text { in residuum }\end{array}$ & $\begin{array}{c}\text { Amount of } \\
\text { andrographolide in } \\
1 \mathrm{~g} \text { of dry plant } \\
(\mu \mathrm{g} / \mathrm{g})\end{array}$ \\
\hline $\begin{array}{c}\text { AP1 } \\
\text { (Papanasam RF) }\end{array}$ & 5 & 1.57 & 0.993 & 11.077 \\
\hline $\begin{array}{c}\text { AP II } \\
\text { (Karayar) }\end{array}$ & 5 & 1.20 & 1.000 & 10.058 \\
\hline $\begin{array}{c}\text { AP III } \\
\text { (Courtallum) }\end{array}$ & 5 & 1.47 & 0.994 & 15.090 \\
\hline $\begin{array}{c}\text { AP IV } \\
\text { (Kalakad) }\end{array}$ & 5 & 1.84 & 0.987 & 3.039 \\
\hline $\begin{array}{c}\text { AP V } \\
\text { (Manimuthar) }\end{array}$ & 5 & 1.94 & 0.841 & 3.567 \\
\hline
\end{tabular}


Plate 3: Andrographis paniculata (Burm.f.) Nees.
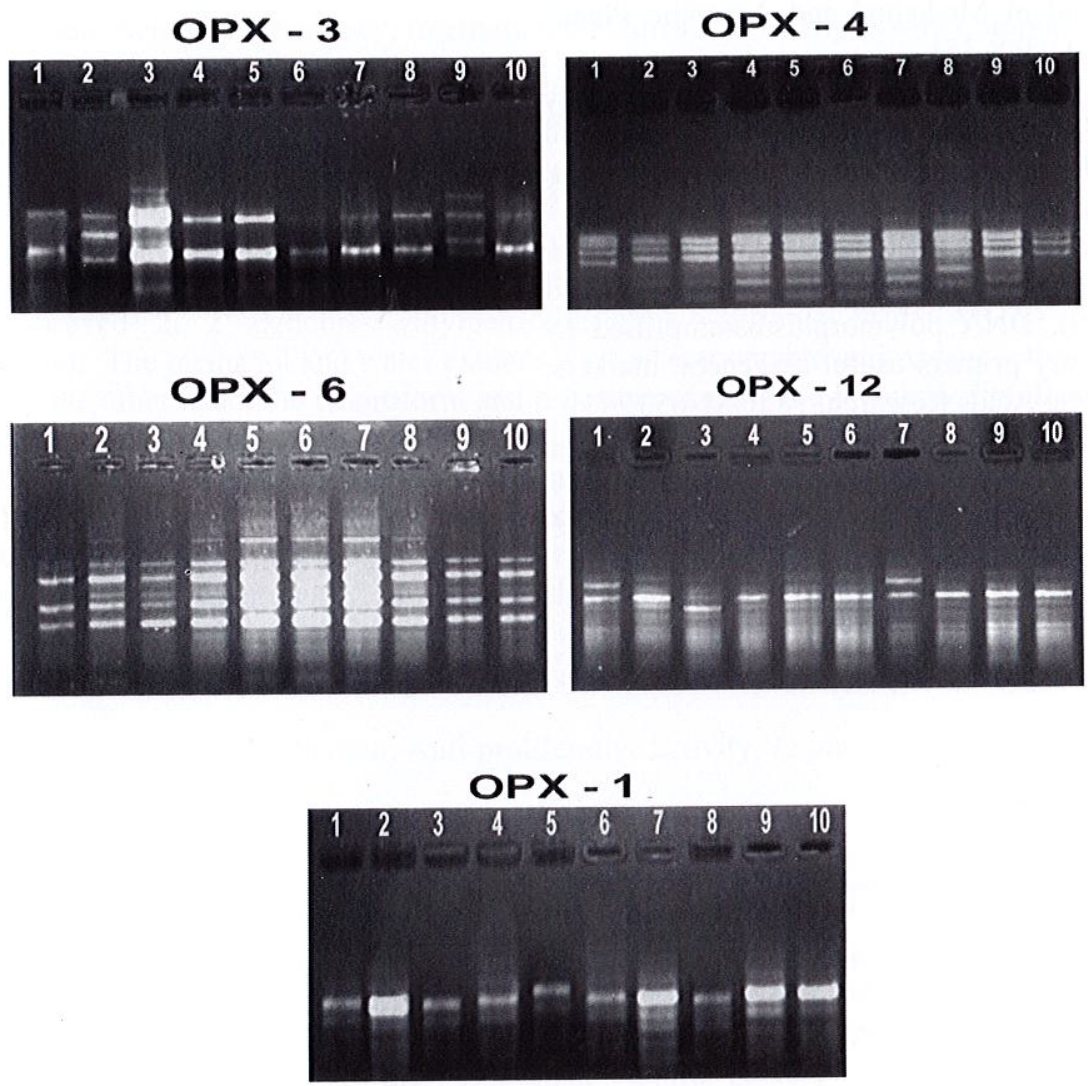

\section{REFERENCES}

1. Li, W. K. and Fitzloff (2002). Determination of andrographolide in commercial Andrographis (Andrographis paniculata) products using HPLC with evaporate light scattering detection. Journal of liquid chromatography \& related technologies, 25(9):1335 - 1343.

2. Wagner, C., Marquard, R. A., Friedt, W. and Ordon, F. (2003). Identification of RAPD and AFLP markers linked to genes determining bisabolol and chamazulene content in Camomile (Chamomilla recutina (L.) RAUSCH). WOCMAP III, Abstracts.
3. Jain, N., Shasamy, A. K., Sundaresan, V., Rajkumar, S., Darokar, M. P., Bagehi, G. D., Gupta, A. K., Sushil Kumar and Khanuja, S. P. S. (2003). Molecular diversity in Phyllanthus amarus assessed through RAPD analysis. Current Science, 85(10): 14541548.

4. Singh, A., Chaudhury, A., Srivastava, P. S. and Lakshmikumaran, M. (2002). Comparison of AFLP and SAMPL markers for assessment of intra-population genetic variation in Azadirachta indica A. Juss. Plant Science, 162(1):17-25.

5. Chatterjie, S. N., Nagaraja, G. M., Srivastava, P. P. and Naik, G. (2005). 
Morphological and molecular variation of Morus laevigata in India. Genetica, 112:133-143.

6. Misra, H. O., Sharma, J. R., Lal, R. K. and Shukla, N. (2000). Pattern of genetic variability traits in a collection of Kalmegh (Andrographis paniculata) genotypes. Journal of Medicinal and Aromatic Plants, 22(4A):348-351.

7. Doyle, J. J., and Doyle, J. L. (1987). Rapid DNA isolation procedures for small quantities of fresh leaf tissues. Phytochemistry, 19:11-15.

8. Williams, J. G. K., Kubelik, A. R., Livak, K. J., Rafalski, J. A. and Tingey, S. V. (1990). DNA polymorphisms-amplified by arbitrary primers useful as genetic markers. Nucleic Acids Research, 18:6531-6535.

9. Nei. (1978). Estimation of average heterozygosity and genetic distance from a small number of individuals. Genetics, 89: 583-590. 